\title{
OCLUSÃO INTESTINAL POR DIVERTÍCULO DE MECKEL GIGANTE: RELATO DE CASO
}

\section{ARTIGO ORIGINAL}

PARRA, Arthur Garrido ${ }^{1}$

MOLINOS, Felipe Nunes ${ }^{2}$

OLIVEIRA, Renato Leão de ${ }^{3}$

PARRA, Arthur Garrido. MOLINOS, Felipe Nunes. OLIVEIRA, Renato Leão de. Oclusão intestinal por divertículo de Meckel gigante: Relato de caso. Revista Científica Multidisciplinar Núcleo do Conhecimento. Ano 05, Ed. 08, Vol. 15, pp. 0511. Agosto de 2020. ISSN: 2448-0959, Link de acesso: https://www.nucleodoconhecimento.com.br/saude/oclusao-intestinal

\section{RESUMO}

Este trabalho tem como objetivo relatar um caso de um divertículo de Meckel gigante causando uma hérnia interna e obstrução intestinal. Sendo este um achado de difícil diagnóstico pré operatório, no qual $\mathrm{RX}$ e a TC mostraram sinais de obstrução, mas não a causa específica. Sendo assim, ressaltamos a importância da habilidade do cirurgião ao achado intraoperatório desta condição. Divertículo de Meckel é considerado uma das anomalias congênitas mais frequentes que acometem o intestino delgado. É resultante de um fechamento incompleto do conduto onfalomesentérico ou saco vitelínico que deveria ocorrer até a oitava semana de gestação, formando uma bolsa tubular. Localiza-se na borda antimesentérica do íleo

\footnotetext{
${ }^{1}$ Graduação em Medicina.

${ }^{2}$ Graduação em Medicina.

${ }^{3}$ Especialização - Residência médica. Graduação em Medicina.
} 
distal, estando há aproximadamente um metro da válvula ileocecal. As complicações decorrentes são incomuns, mas podem incluir sangramento, obstrução e diverticulite.

Palavras-chave: Oclusão intestinal, divertículo de Meckel.

\section{INTRODUÇÃO}

Divertículo de Meckel é considerado uma das anomalias congênitas mais frequentes que acometem o intestino delgado. É resultante de um fechamento incompleto do conduto onfalomesentérico ou saco vitelínico (CAPELÃO et al., 2017) que deveria ocorrer até a oitava semana de gestação, formando uma bolsa tubular (HARRIS et al., 2017). Localiza-se na borda antimesentérica do íleo distal, estando há aproximadamente um metro da válvula ileocecal (HARRIS et al., 2017). As complicações decorrentes são incomuns, mas podem incluir sangramento, obstrução e diverticulite (HARRIS et al., 2017).

\section{RELATO DO CASO}

Paciente de 15 anos, sexo masculino, sadio, com antecedente de apendicectomia há um ano. Deu entrada no serviço de emergência relatando há dois dias vários episódios de vômitos de aspecto biliar, dor moderada em cólica no mesogástrio, e diminuição das evacuações e gases. Ao exame físico geral, mostrou-se desidratado. Abdome com discreta distensão, ruídos hidroaéreos metálicos, hiper timpânicos, e doloroso à palpação profunda difusa, sem sinais de irritação peritoneal. Ausência de massas palpáveis e não identificado hérnia inguinal. Toque retal com vestígios fecais.

Tabela 1. Exames laboratoriais de admissão.

\begin{tabular}{|l|l|}
\hline HB & $\mathbf{1 7 , 1}$ \\
\hline LEUCÓCITOS & 10.400 \\
\hline PLAQUETAS & 272.000 \\
\hline CREATININA & 1,10 \\
\hline URÉIA & 34 \\
\hline
\end{tabular}




\begin{tabular}{|l|l|}
\hline NA & 142 \\
\hline K & 3,8 \\
\hline PCR & 164,2 \\
\hline
\end{tabular}

Fonte: autores.

Figura 1. Radiografia simples. Distensão de alças intestinais com presença de níveis hidroaéreos

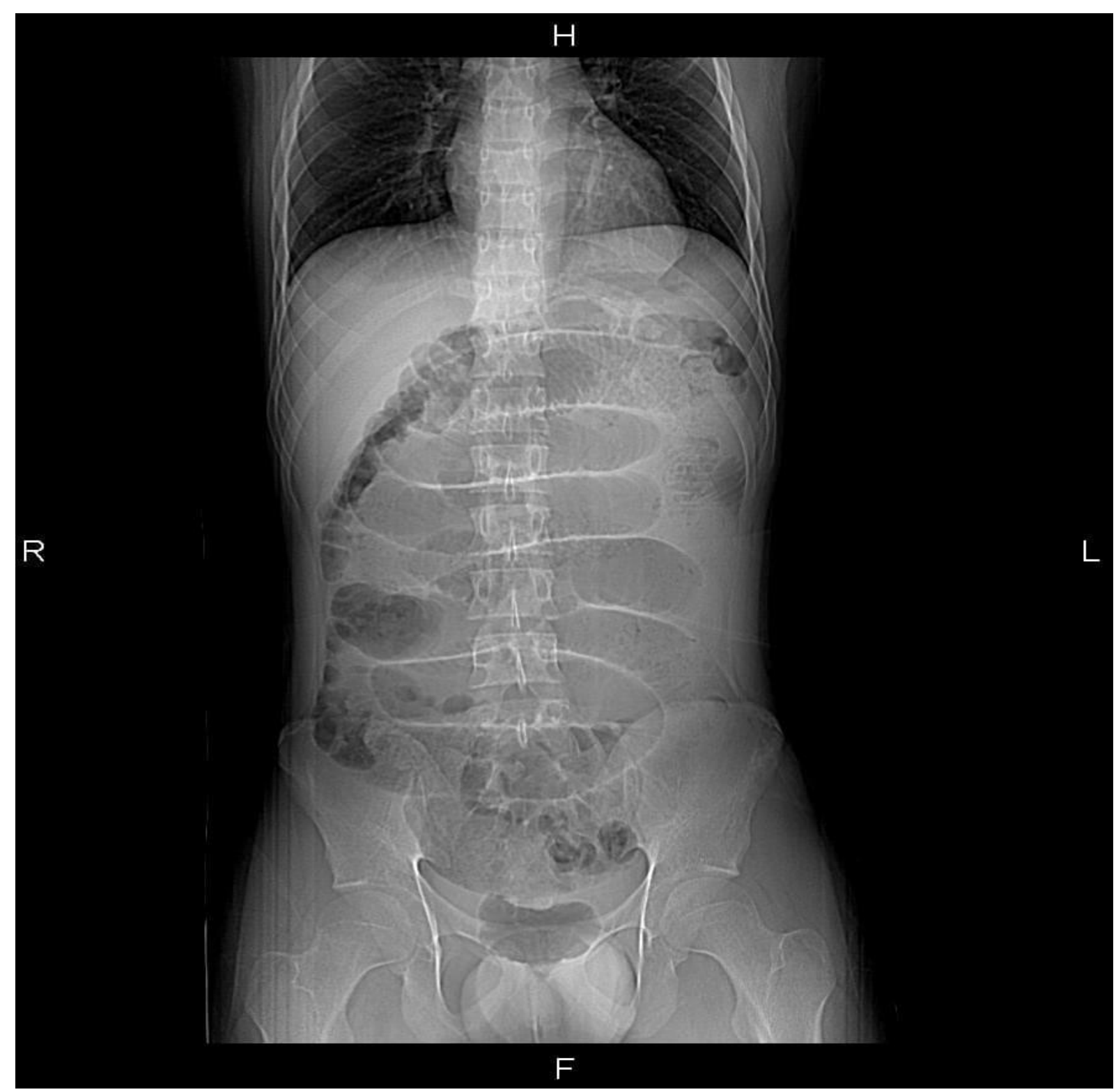

Fonte: autores.

RC: 57732

Disponível em: https://www.nucleodoconhecimento.com.br/saude/oclusao-intestinal 
Figura 2. Tomografia computadorizada de abdome de admissão do paciente. Seta branca indicando o divertículo.

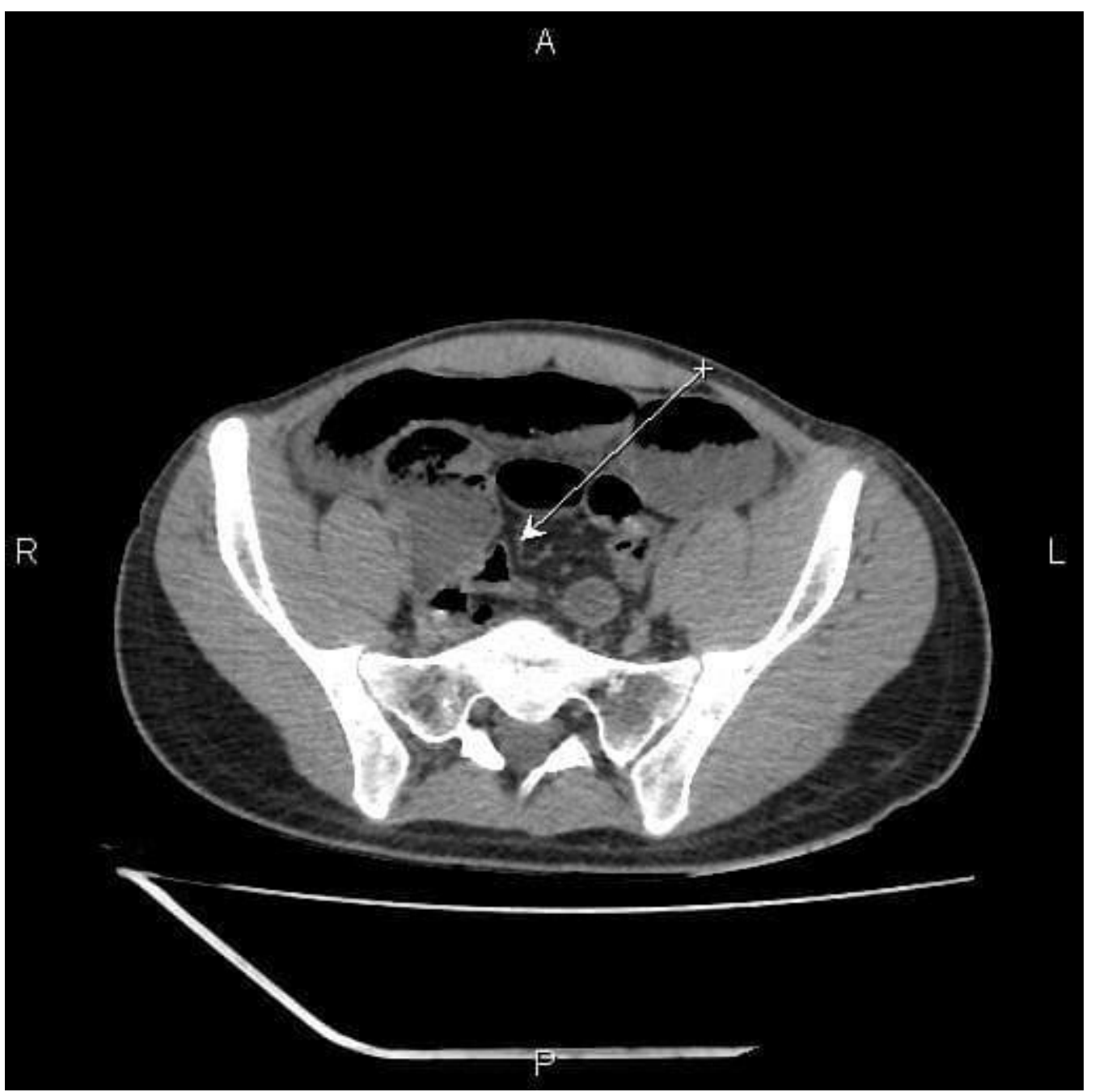

Fonte: autores. 
Figura 3. Tomografia computadorizada de admissão do paciente. Seta branca indicando torção dos vasos mesentéricos e aparente ponto de mudança no calibre da alça em íleo terminal.

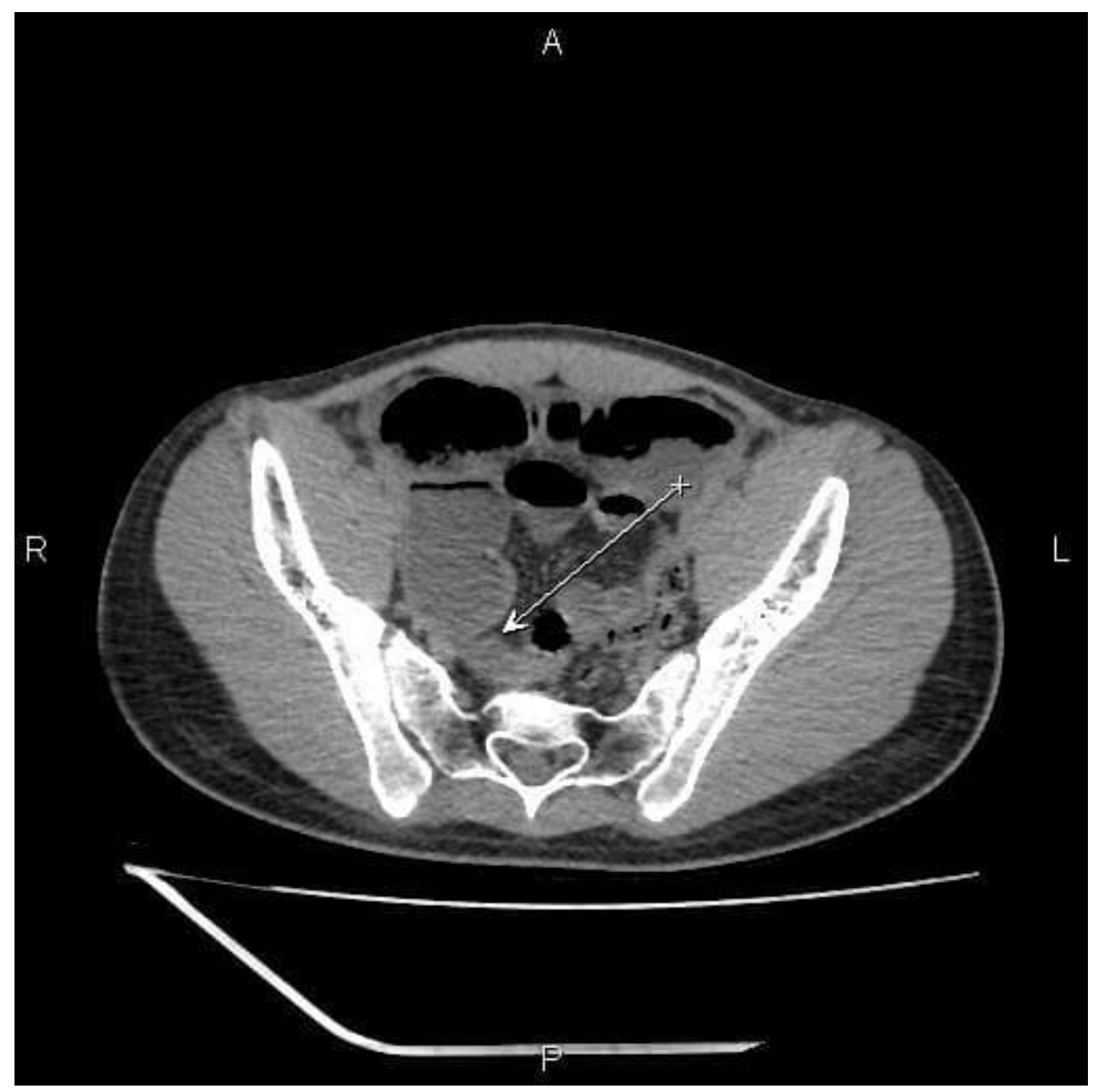

Fonte: autores.

Foram realizadas as medidas básicas do abdome agudo obstrutivo, solicitados exames laboratoriais (tabela 1) e exames de imagem (figuras 1, 2 e 3). As aderências intestinais decorrentes da apendicite prévia foi o diagnóstico etiológico pensado inicialmente como a causa do abdome agudo obstrutivo. 
O RX e a TC mostraram sinais de obstrução e torção dos vasos do mesentério, mas não a causa específica (figura 3 ). Estes achados em exames de imagem foram indicativos de laparotomia exploradora de urgência.

No intraoperatório identificou-se um divertículo gigante (figuras 4 e 5), com aproximadamente $15 \mathrm{~cm}$ de extensão e $4 \mathrm{~cm}$ de diâmetro, fazendo uma herniação no mesentério ligada por um cordão fibroso, causando obstrução e distensão do intestino a montante, sem isquemia de alças intestinais.

Realizado a ressecção do divertículo, em cunha na base, e rafia em dois planos com pontos separados.

Figuras 4 e 5 . Achados intraoperatório de divertículo medindo aproximadamente 15 centímetros de extensão e 4 centímetros de diâmetro.

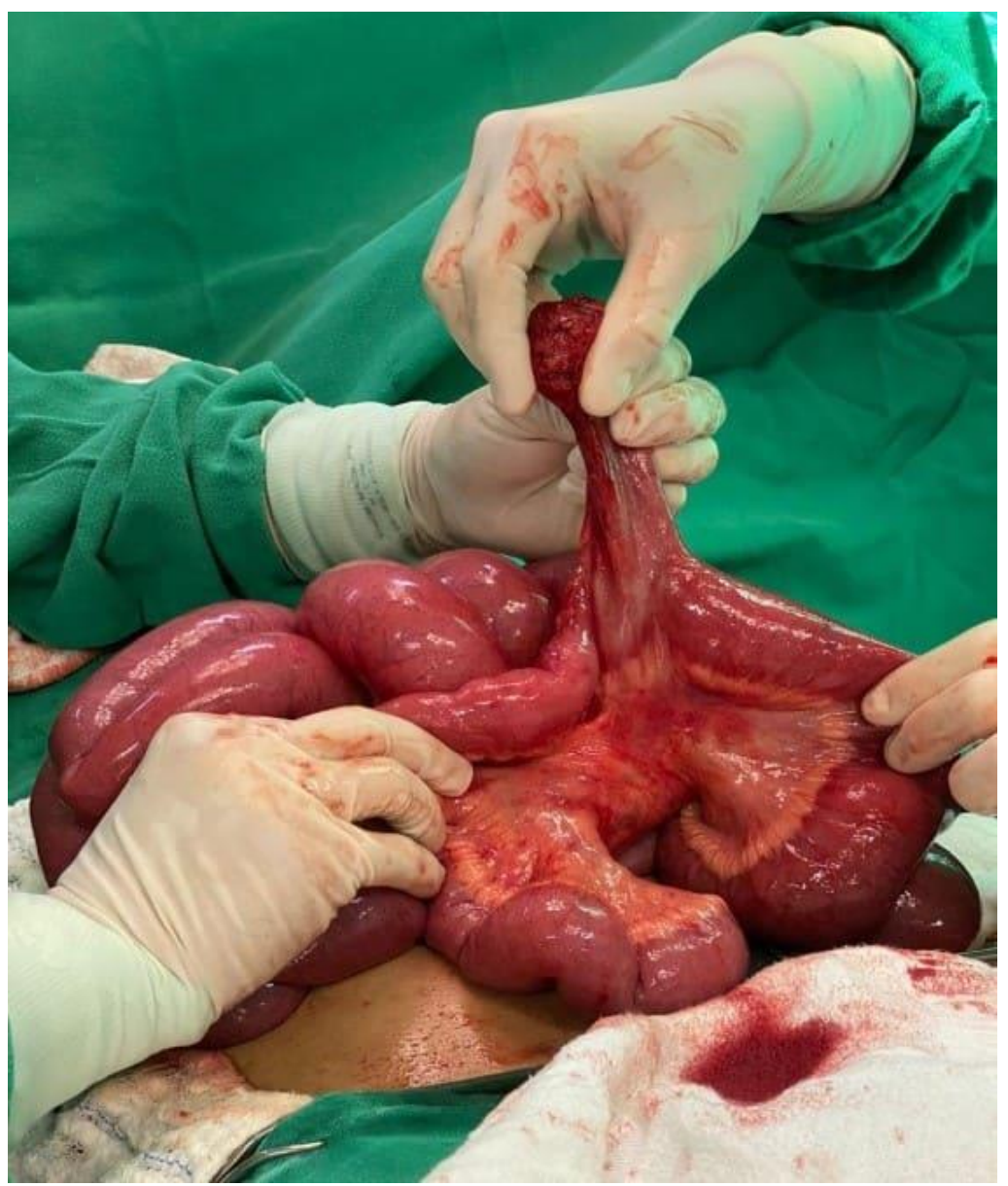

Fonte: autores.

$\mathrm{RC}: 57732$

Disponível em: https://www.nucleodoconhecimento.com.br/saude/oclusao-intestinal 


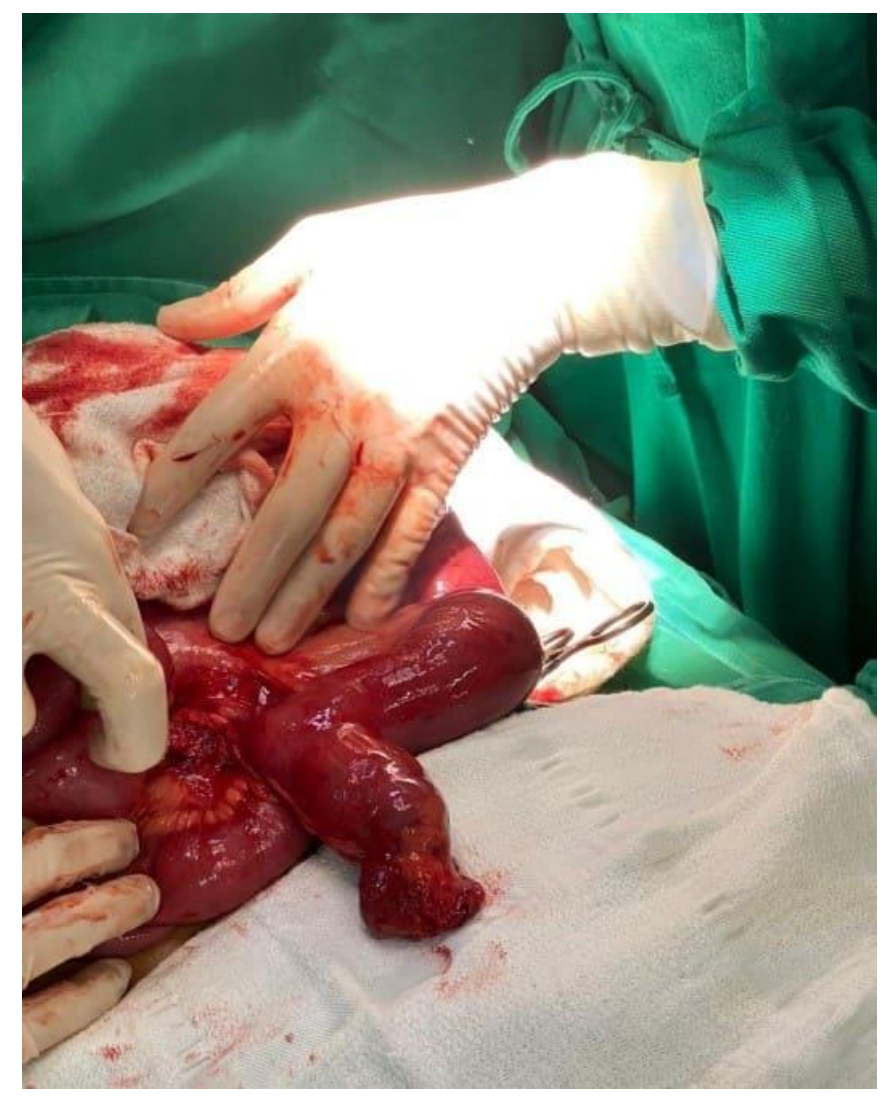

Fonte: autores.

Foi prescrita dieta parenteral por uma semana e introdução gradual da alimentação.

O paciente retirou a sonda nasogástrica no primeiro dia após a cirurgia e ingeriu alimentos precoce sem autorização médica. Somando-se ao fato que existia um íleo adinâmico, o quadro evoluiu com distensão abdominal, aumento da pressão intraintestinal e abdominal, e vômitos, causando a deiscência da anastomose intestinal e a eventração. No sétimo dia de pós-operatório, o paciente evoluiu com deiscência total da parede abdominal e da anastomose intestinal, sendo novamente submetido à laparotomia, com drenagem de moderada quantidade de secreção entérica e purulenta na cavidade. Realizado enterectomia segmentar e anastomose entero-entérica término terminal em dois planos com pontos separados. Colocado dreno tubular ao redor da anastomose, goteiras parietocólicas e pelve. 
Houve contaminação e infecção por Klebsiella confirmada na cultura. O trânsito intestinal, com retorno alimentar normal, e a cura da infecção foi obtida por volta do vigésimo dia de internação. O íleo adinâmico durou por volta de duas semanas.

O resultado anatomopatológico confirmou metaplasia gástrica em dois focos de $5 \mathrm{~mm}$ e $4 \mathrm{~mm}$.

\section{DISCUSSÃO}

Divertículo de Meckel é um divertículo verdadeiro, considerado uma das anomalias congênitas mais frequentes que acometem o intestino delgado. Localiza-se na borda antimesentérica do íleo distal, estando aproximadamente há um metro da válvula ileocecal, mas podendo variar de 40 a $150 \mathrm{~cm}$ em média (HARRIS et al., 2017). É resultante de um fechamento incompleto do conduto onfalomesentérico ou saco vitelínico que deveria ocorrer até a oitava semana de gestação (CAPELÃO et al., 2017), formando uma bolsa tubular desde um pequeno abaulamento até uma projeção longa que se comunica com o umbigo por um cordão fibroso persistente (CAPELÃO et al., 2017).

É observada a presença de mucosa heterotópica em aproximadamente $65 \%$ dos casos, podendo conter tecido gástrico, pancreático, colônico, endometrióide e tecido hepatobiliar (HARRIS et al., 2017). As complicações decorrentes são incomuns, mas podem incluir sangramento (40 a 50\%), obstrução (30\%) e diverticulite $(20 \%)$, acometendo principalmente jovens do sexo masculino (HARRIS et al., 2017).

O sangramento intestinal decorre de úlceras na mucosa ileal adjacente à mucosa heterotópica do divertículo produtora de ácido (HARRIS et al., 2017). Nas obstruções, o intestino delgado pode formar uma hérnia interna, com o mesentério, pela persistência de conduto fibrótico remanescente do conduto onfalomesentérico (HARRIS et al., 2017). O próprio divertículo livre pode servir como ponto de intussuscepção ou volvo. Estenose secundária a diverticulite crônica também é possível de ocorrer. Outra causa é o encarceramento do divertículo em uma hérnia inguinal (Hérnia de Littré). 
A diverticulite é responsável por 10 a $20 \%$ das complicações, sendo o quadro clínico semelhante a apendicite aguda, podendo evoluir com perfuração e peritonite (HARRIS et al., 2017).

O Diagnóstico pré-operatório é incomum, sendo na maioria das vezes descoberto durante a laparotomia ou laparoscopia. Os exames que fazem parte da investigação são a radiografia simples, o enema baritado, a ultra-sonografia, a tomografia computadorizada e a cintilografia com tecnécio 99, sendo este último o método de maior acurácia para detectar o divertículo de Meckel (HARRIS et al., 2017). Esse radio nucleotídeo é captado e secretado pelas células secretoras da mucosa gástrica heterotópica (HARRIS et al., 2017). Caso a mucosa presente no interior do divertículo seja pancreática ou colônica, o tecnécio não será captado no exame, sendo o diagnóstico definitivo feito através do anatomopatológico.

\section{CONCLUSÃO}

O Divertículo de Meckel gigante gerando obstrução intestinal é uma condição considerada rara (CAPELÃO et al., 2017), a qual requer métodos diagnósticos não disponíveis em todos os serviços de saúde, o que torna seu diagnostico um grande desafio, sendo necessário realizar laparotomia exploradora e a análise anatomopatológica para a confirmação do caso. A introdução alimentar precoce e de forma não regrada pode causar a deiscência da anastomose causando complicações mais graves e tempo de internação prolongado.

Qual o método cirúrgico que teria melhores resultados e menores chances de complicações fica ainda em discussão. Cada cirurgião deve decidir no ato cirúrgico a melhor opção, levando em conta sua experiência, a distância do divertículo da válvula ileocecal e o estado clínico do paciente. A nossa conduta primária foi a ressecção em cunha com rafia lateral em dois planos, porém evoluindo com deiscência total. Melhores resultados talvez teríamos se tivéssemos optado de início pela enterectomia segmentar com anastomose término-terminal. 


\section{REFERÊNCIAS}

CAPELÃO, G. et. al., Olusão Intestinal por Divertículo de Meckel Gigante. GEPortuguese Journal of Gastroenterology, Lisboa, v. 24, n. 04, agosto 2017. GE Port J Gastroenterol vol.24 no.4 Lisboa ago. 2017.

HARRIS, Jennifer; EVERS, B. Intestino Delgado: Doença diverticular. In: TOWNSEND, Courtney et al. Sabiston Tratado de Cirurgia: A Base Biológica da Prática Cirurgica Moderna. 20. ed. [S. I.]: Elsevier, Inc., 2017. cap. 49, p. 1280-1285.

VIDAL, Mário. OBSTRUÇÃO INTESTINAL : CAUSAS E CONDUTAS. Revista Brasileira de Coloproctologia, [S. I.], v. 25, n. 04, p. 332-338, 2005. Rev bras Coloproct, 2005.

Enviado: Agosto, 2020.

Aprovado: Agosto, 2020. 